\title{
Enhanced Visible-Light-Sensitive Two-Step Overall Water-Splitting Based on Band Structure Controls of Titanium Dioxide and Strontium Titanate
}

\author{
Satoshi Tanigawa1, Toshihiro Takashima1,2, Hiroshi Irie ${ }^{1,2 *}$ \\ ${ }^{1}$ Special Doctoral Program for Green Energy Conversion Science and Technology, Interdisciplinary Graduate School of Medicine \\ and Engineering, University of Yamanashi, Yamanashi, Japan \\ ${ }^{2}$ Clean Energy Research Center, University of Yamanashi, Yamanashi, Japan \\ Email: ^hirie@yamanashi.ac.jp
}

How to cite this paper: Tanigawa, S., Takashima, T. and Irie, H. (2017) Enhanced Visible-Light-Sensitive Two-Step Overall Water-Splitting Based on Band Structure Controls of Titanium Dioxide and Strontium Titanate. Journal of Materials Science and Chemical Engineering, 5, 129-141. http://dx.doi.org/10.4236/msce.2017.51017

Received: December 22, 2016

Accepted: January 20, 2017

Published: January 23, 2017

Copyright (๑) 2017 by authors and Scientific Research Publishing Inc. This work is licensed under the Creative Commons Attribution International License (CC BY 4.0).

http://creativecommons.org/licenses/by/4.0/

\begin{abstract}
Visible light-induced two-step overall water-splitting was achieved by combining two types of photocatalysts, which were prepared by introducing foreign elements into rutile titanium dioxide $\left(\mathrm{TiO}_{2}\right)$ and strontium titanate $\left(\mathrm{SrTiO}_{3}\right)$ with a controlled electronic band structure. Rutile $\mathrm{TiO}_{2}$ and $\mathrm{SrTiO}_{3}$ were doped with chromium and tantalum $\left(\mathrm{Cr}, \mathrm{Ta}-\mathrm{TiO}_{2}\right)$ and with rhodium $\left(\mathrm{Rh}-\mathrm{SrTiO}_{3}\right)$, respectively, to introduce visible-light sensitivity. Under irradiation with only visible light from a 420-nm LED lamp, the simultaneous liberation of hydrogen and oxygen with a molar ratio of $\sim 2: 1$ was achieved with these two types of photocatalysts in the presence of iodate ion/iodide ion as a redox mediator.
\end{abstract}

\section{Keywords}

Titanium Dioxide, Strontium Titanate, Visible Light, Overall Water-Splitting, Two-Step Excitation

\section{Introduction}

Various photocatalytic materials have been evaluated for water splitting activity because the generated hydrogen $\left(\mathrm{H}_{2}\right)$ represents a clean and renewable fuel source [1] [2] [3]. Among examined materials, titanium dioxide $\left(\mathrm{TiO}_{2}\right)$ with which Fujishima and Honda first demonstrated photoinduced water-splitting [1] and strontium titanate $\left(\mathrm{SrTiO}_{3}\right)$ [4], are the most promising photocatalysts due to their abundance, nontoxicity, thermal stability and high resistance against 
photo-corrosion. Despite these advantageous properties, both $\mathrm{TiO}_{2}$ and $\mathrm{SrTiO}_{3}$ are only sensitive to ultraviolet (UV) light and therefore requires modification for the utilization of visible light. To this end, numerous studies have examined the effects of doping foreign elements into $\mathrm{TiO}_{2}$ and $\mathrm{SrTiO}_{3}$ on visible-light induced water-splitting [5] [6] [7] [8]. Although a sacrificial agent is needed, the doped $\mathrm{TiO}_{2}$ and $\mathrm{SrTiO}_{3}$ are able to generate either $\mathrm{H}_{2}$ or oxygen $\left(\mathrm{O}_{2}\right)$ following irradiation with visible light (half reaction of water-splitting).

Combined systems consisting of two specific photocatalysts for $\mathrm{H}_{2}$ and $\mathrm{O}_{2}$ production $\left(\mathrm{H}_{2}\right.$-photocatalyst and $\mathrm{O}_{2}$-photocatalyst, respectively) and a suitable redox mediator can function as visible-light sensitive photocatalysts for overall water-splitting (termed two-step overall water-splitting or Z-scheme overall water-splitting) [9]-[18]. The well-known combination is platinum (Pt)-deposited chromium (Cr) and tantalum (Ta)-codoped $\mathrm{SrTiO}_{3}$ or ruthenium $(\mathrm{Ru})$-deposited rhodium (Rh)-doped $\mathrm{SrTiO}_{3}$ as the $\mathrm{H}_{2}$-photocatalyst, and Pt-deposited tungsten trioxide $\left(\mathrm{WO}_{3}\right)$ or bismuth vanadate $\left(\mathrm{BiVO}_{4}\right)$ as the $\mathrm{O}_{2}$-photocatalyst [10] [11]. The $\mathrm{Z}$-scheme systems require the suitable redox mediator, such as iodate $\left(\mathrm{IO}_{3}^{-}\right)$/iodide $\left(\mathrm{I}^{-}\right)$or ferric $\left(\mathrm{Fe}^{3+}\right) /$ ferrous $\left(\mathrm{Fe}^{2+}\right)$ ions. Recently, solid-state Zscheme systems that function in the absence of a redox mediator have been reported [13]-[18].

Our group have successfully synthesized a combined system consisting of only one mother material, $\mathrm{TiO}_{2}$-based photocatalysts (Pt-deposited anatase $\mathrm{Ti}_{0.96} \mathrm{Cr}_{0.02} \mathrm{Ta}_{0.02} \mathrm{O}_{2}\left(\mathrm{Pt}_{/} / \mathrm{Ti}_{0.96} \mathrm{Cr}_{0.02} \mathrm{Ta}_{0.02} \mathrm{O}_{2}\right)$ and Pt-deposited rutile $\mathrm{Ti}_{0.982} \mathrm{Cr}_{0.009} \mathrm{Ta}_{0.009} \mathrm{O}_{2}$ ( $\left.\mathrm{Pt} / \mathrm{Ti}_{0.982} \mathrm{Cr}_{0.009} \mathrm{Ta}_{0.009} \mathrm{O}_{2}\right)$ as the $\mathrm{H}_{2^{-}}$and $\mathrm{O}_{2}$-photocatalyst, respectively) and $\mathrm{SrTiO}_{3}$-based photocatalysts (Ru-deposited $\operatorname{Sr}\left(\mathrm{Ti}_{0.99} \mathrm{Rh}_{0.01}\right) \mathrm{O}_{3}$ and $\mathrm{Ru}$-deposited $\left(\mathrm{Sr}_{0.99} \mathrm{Na}_{0.01}\right)\left(\mathrm{Ti}_{0.99} \mathrm{~V}_{0.01}\right) \mathrm{O}_{3}$, as the $\mathrm{H}_{2^{-}}$and $\mathrm{O}_{2}$-photocatalyst, respectively) [19] [20]. Based on the activities of the systems, it was conceivable that visible-lightsensitive two-step overall water-splitting system could be improved by utilizing the $\mathrm{SrTiO}_{3}$ - and $\mathrm{TiO}_{2}$-based materials as $\mathrm{H}_{2}$ - and $\mathrm{O}_{2}$-photocatalysts, respectively. The construction of such a system may be advantageous because they have properties, such as nontoxicity, stability, and natural abundance, which are expected to facilitate their use in industrial and practical applications by contrast with utilization of $\mathrm{WO}_{3}$ or $\mathrm{BiVO}_{4}$.

In the present study, we combined $\mathrm{Cr}$ - and Ta-codoped $\mathrm{TiO}_{2}$ and $\mathrm{Rh}$-doped $\mathrm{SrTiO}_{3}$, and achieved the $\mathrm{H}_{2}$ - and $\mathrm{O}_{2}$-evolution rates derived from two-step overall watersplitting $~ 100$ times larger irradiated with 420 -nm visible-light.

\section{Experimental Section}

\subsection{Preparations of $\mathrm{TiO}_{2}$-Based and $\mathrm{SrTiO}_{3}$-Based Photocatalysts}

Cr- and Ta-codoped rutile $\mathrm{TiO}_{2}\left(\mathrm{Ti}_{0.986} \mathrm{Cr}_{0.007} \mathrm{Ta}_{0.007} \mathrm{O}_{2}, \mathrm{Cr}, \mathrm{Ta}-\mathrm{TiO}_{2}\right)$ as an $\mathrm{O}_{2}$ evolution photocatalyst was prepared by a hydrothermal synthesis method using commercial $\mathrm{Ti}\left(\mathrm{SO}_{4}\right)_{2}$ (24.0\% purity, $3.97 \times 10^{-2} \mathrm{~mol}$; Kanto Kagaku), $\mathrm{CrCl}_{3} \cdot 6 \mathrm{H}_{2} \mathrm{O}$ $\left(1.40 \times 10^{-4} \mathrm{~mol}\right.$; Kanto Kagaku), and $\mathrm{TaCl}_{5}\left(1.40 \times 10^{-4} \mathrm{~mol}\right.$; Kanto Kagaku $)$ as starting materials. The starting materials for the form of $\mathrm{Cr}, \mathrm{Ta}-\mathrm{TiO}_{2}$ were mixed and stirred in distilled water for $30 \mathrm{~min}$ using a magnetic stirrer. The solutions 
were treated hydrothermally in an autoclave at $140^{\circ} \mathrm{C}$ for $12 \mathrm{~h}$, and the resulting mixtures were washed with sufficient distilled water, collected by centrifugation, and dried at $80^{\circ} \mathrm{C}$ overnight. The dried mixtures were calcined at $900^{\circ} \mathrm{C}$ for $24 \mathrm{~h}$, and were then thoroughly ground using a mortar and pestle. As a reference, non-doped rutile $\left(\mathrm{TiO}_{2}\right)$ was prepared under identical conditions using only $\mathrm{Ti}\left(\mathrm{SO}_{4}\right)_{2}$.

Rh-doped $\mathrm{SrTiO}_{3}\left(\mathrm{Sr}\left(\mathrm{Ti}_{0.99} \mathrm{Rh}_{0.01}\right) \mathrm{O}_{3}, \mathrm{Rh}-\mathrm{SrTiO}_{3}\right)$ was synthesized using a conventional solid-state reaction. Commercial $\mathrm{SrCO}_{3}$ (Kanto Kagaku, purity 99.9\%), $\mathrm{TiO}_{2}$ (High Purity Chemicals, purity 99.99\%), and $\mathrm{Rh}_{2} \mathrm{O}_{3}$ (Kanto Kagaku, purity 99.9\%) powders were used as the starting materials. Stoichiometric amounts of the starting materials for $\mathrm{Rh}-\mathrm{SrTiO}_{3}$ were wet-ball-milled (200 rpm) for $20 \mathrm{~h}$ using zirconium dioxide $\left(\mathrm{ZrO}_{2}\right)$ balls as the milling medium in polyethylene bottles. The resulting mixture was calcined at $1000^{\circ} \mathrm{C}$ for $10 \mathrm{~h}$ and then thoroughly ground to obtain $\mathrm{Rh}-\mathrm{SrTiO}_{3}$ powder. As a reference, non-doped $\mathrm{SrTiO}_{3}$ was prepared under identical conditions using only $\mathrm{SrCO}_{3}$ and $\mathrm{TiO}_{2}$.

The deposition of either Pt or Ru co-catalyst onto the synthesized $\mathrm{Cr}, \mathrm{Ta}-\mathrm{TiO}_{2}$ or $\mathrm{Ru}-\mathrm{SrTiO}_{3}$ photocatalysts, respectively, was performed by a photo-deposition method. Briefly, $0.5 \mathrm{~g}$ of either $\mathrm{Cr}, \mathrm{Ta}-\mathrm{TiO}_{2}$ or $\mathrm{Ru}-\mathrm{SrTiO}_{3}$ powder was first dispersed in $100 \mathrm{~mL}$ methanol solution (20 vol\%) as a hole scavenger. The amount of $\mathrm{H}_{2} \mathrm{PtCl}_{6} \cdot 6 \mathrm{H}_{2} \mathrm{O}$ (98.5\% purity; Kanto Kagaku) as the source of Pt needed to give a weight fraction of $\mathrm{Pt}$ relative to $\mathrm{Cr}, \mathrm{Ta}-\mathrm{TiO}_{2}$ of $1 \times 10^{-3}$ was weighted. $\mathrm{Ru}$ thenium chloride $\left(\mathrm{RuCl}_{3} \cdot \mathrm{nH}_{2} \mathrm{O}, \mathrm{n}\right.$ was assumed to be 3$)$, which served as the source of $\mathrm{Ru}$, was weighed to give a weight fraction of $\mathrm{Ru}$ relative to $\mathrm{Rh}-\mathrm{SrTiO}_{3}$ of $7 \times 10^{-3}$. Weighed $\mathrm{H}_{2} \mathrm{PtCl}_{6} \cdot 6 \mathrm{H}_{2} \mathrm{O}$ or $\mathrm{RuCl}_{3} \cdot \mathrm{nH}_{2} \mathrm{O}$ was added to each aqueous sample suspension, which was then sufficiently deaerated using liquid nitrogen $\left(\mathrm{N}_{2}\right)$. While deaerating the suspensions, a xenon (Xe) lamp (LA-251 Xe; Hayashi Tokei) equipped with an optical filter (Y-44, Hoya) was employed for light irradiation of the suspension for $4 \mathrm{~h}$. The suspension was then centrifuged, washed with distilled water, and the resulting residues were dried at $80^{\circ} \mathrm{C}$ overnight. The residues were ground into a fine powder using an agate mortar to obtain the Pt-deposited $\mathrm{Cr}, \mathrm{Ta}-\mathrm{TiO}_{2}\left(\mathrm{Pt} / \mathrm{Cr}, \mathrm{Ta}-\mathrm{TiO}{ }_{2}\right)$ and $\mathrm{Ru}$-deposited $\mathrm{Rh}-\mathrm{SrTiO}_{3}$ $\left(\mathrm{Ru} / \mathrm{Rh}-\mathrm{SrTiO}_{3}\right)$ photocatalyst powders.

\subsection{Characterizations}

The crystal structures of the prepared powders were examined by X-ray diffraction (XRD) using a PW-1700 system (Panalytical). Brunauer-Emmett-Teller (BET) surface areas were determined using a nitrogen adsorption apparatus (Micromeritics, TriStar 3000; Shimadzu). The valency of the constituent elements was measured by X-ray photoelectron spectroscopy (XPS; Axis-Ultra, Shimadzu). UV-visible absorption spectra were obtained by the diffuse reflection method using a V-650 (JASCO) spectrometer. Quantitative analyses were performed by X-ray fluorescence (XRF) using a ZSXP PrimusII system (Rigaku). A scanning transmission electron microscope (STEM, Tecnai Osiris, FEI) were used to observe the morphology of the prepared photocatalysts. 


\subsection{Photocatalytic Water-Splitting Tests}

Two types of photocatalytic water-splitting tests (half reactions of water-splitting and two-step overall water-splitting) were performed in a gas-closed-circulation system, which was filled with argon gas $(50 \mathrm{kPa})$ after deaeration. The amounts of evolved $\mathrm{H}_{2}$ and $\mathrm{O}_{2}$ were monitored using an online gas chromatograph (GC-8A; Shimadzu). Each time we performed the water-splitting experiments, a different amount of $\mathrm{N}_{2}$ was detected. We repeatedly deaerated this system to a final pressure of $2.5 \mathrm{~Pa}$ and then introduced argon gas into the system in the same way. For these reasons, we considered that the detection of $\mathrm{N}_{2}$ originated from the intruded air from outside, and the effect of residual $\mathrm{O}_{2}\left(\right.$ and $\left.\mathrm{N}_{2}\right)$ in water was possibly excluded [19] [20] [21]. Thus, if $\mathrm{N}_{2}$ was detected, the $\mathrm{O}_{2}$ amount was calculated using the following equation: $\mathrm{O}_{2}=$ obs. $\mathrm{O}_{2}-$ (obs. $\left.\mathrm{N}_{2} / 0.78\right) \times 0.21$.

$\mathrm{H}_{2}$ and $\mathrm{O}_{2}$ evolution derived from the half reaction of water-splitting was monitored in the presence of $\mathrm{Ru} / \mathrm{Rh}-\mathrm{SrTiO}_{3}$ or $\mathrm{Pt} / \mathrm{Cr}, \mathrm{Ta}-\mathrm{TiO}_{2}(60 \mathrm{mg}$ each) with the aid of iodide ion $\left(\mathrm{I}^{-}\right)$(sodium iodide (NaI), 99.5\% purity, $0.01 \mathrm{~mol} / \mathrm{L}$ Kanto Kagaku) or iodate ion $\left(\mathrm{IO}_{3}^{-}\right)$(sodium iodate $\left(\mathrm{NaIO}_{3}\right), 99.5 \%$ purity, $0.01 \mathrm{~mol} / \mathrm{L}$; Kanto Kagaku), respectively, as a sacrificial agent. The examinations were conducted in $10 \mathrm{~mL}$ of solution, without adjusting the $\mathrm{pH}$, with constant stirring using a magnetic stirrer and under irradiation with visible light generated from a light-emitting diode (LED) lamp with a wavelength of $420 \mathrm{~nm}$ (420 nm-LED, LEDH60-420, Hamamatsu Photonics). Two-step overall water-splitting experiments were conducted by adding the sample powders $\left(\mathrm{Ru} / \mathrm{Rh}-\mathrm{SrTiO}_{3}: 10 \mathrm{mg}\right.$, $\mathrm{Pt} / \mathrm{Cr}, \mathrm{Ta}-\mathrm{TiO}_{2}: 50 \mathrm{mg}$ ) to $10 \mathrm{~mL} \mathrm{IO}_{3}^{-}$solution as a starting redox mediator without $\mathrm{I}^{-}$. The suspension was constantly stirred using a magnetic stirrer and the $\mathrm{pH}$ was not adjusted. The $420 \mathrm{~nm}$-LED light was used for light irradiation.

\section{Results and Discussion}

\subsection{Characterization of the Prepared Photocatalysts}

Elemental analysis by XRF indicated that the molar ratio of Ti:Cr:Ta in $\mathrm{Pt} / \mathrm{Cr}, \mathrm{Ta}-\mathrm{TiO}_{2}$ was $0.994: 0.002: 0.004$. Notably, this molar ratio was not consistent with the starting ratios used in the preparation of the photocatalyst. This discrepancy was attributed to differences in the solubility of $\mathrm{Ti}, \mathrm{Cr}$ and $\mathrm{Ta}$ in aqueous solution under hydrothermal conditions. The analysis also indicated that the molar fraction of Pt relative to $\mathrm{Cr}, \mathrm{Ta}-\mathrm{TiO}_{2}$ was $1 \times 10^{-4}$. The analysis indicated that the molar ratios of Sr:Ti:Rh in $\mathrm{Rh} / \mathrm{Rh}-\mathrm{SrTiO}_{3}$ was 0.493:0.493:0.014 nearly equal to the starting fractions used in the preparation. The $\mathrm{Ru}$ amount relative to $\mathrm{Rh}-\mathrm{SrTiO}_{3}$ was observed to be $1 \times 10^{-2}$.

$\mathrm{Cr}, \mathrm{Ta}-\mathrm{TiO}_{2}$ was confirmed to have a single phase of rutile $\mathrm{TiO}_{2}$, in the obtained XRD spectrum (Figure $1(\mathrm{a})$ ). In addition, the XRD peaks of $\mathrm{Cr}, \mathrm{Ta}-\mathrm{TiO}_{2}$ were shifted to a lower $2 \theta$ angle compared to non-doped $\mathrm{TiO}_{2}$ (Figure $1(\mathrm{~b})$ ). These results are reasonable when one considers that the effective ionic radii of $\mathrm{Ti}^{4+}, \mathrm{Cr}^{3+}$, and $\mathrm{Ta}^{5+}$ (six-coordination) are $0.0605,0.0615$, and $0.064 \mathrm{~nm}$, 

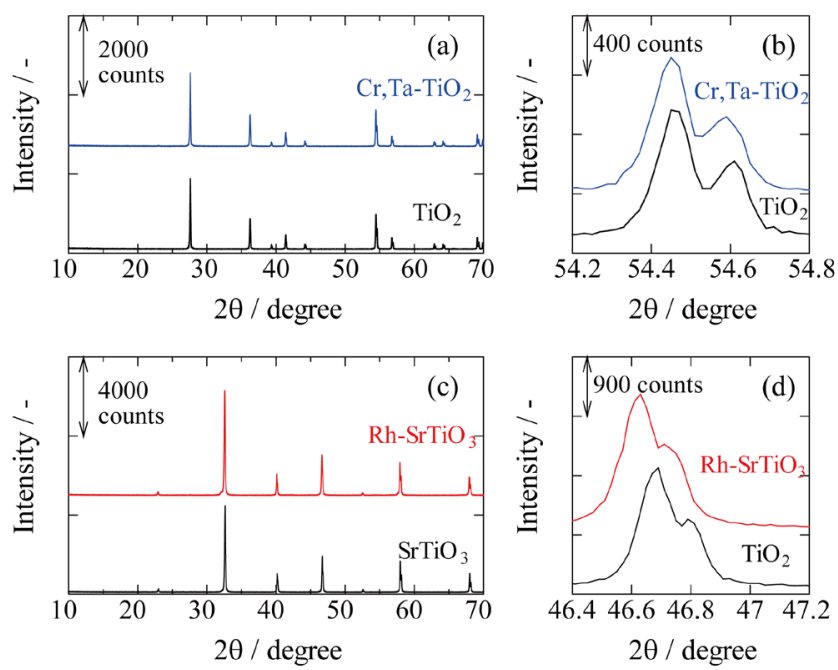

Figure 1. XRD patterns of prepared $\mathrm{TiO}_{2}$ and $\mathrm{Cr}, \mathrm{Ta}-\mathrm{TiO}_{2}$ powders (a), and $\mathrm{SrTiO}_{3}$ and $\mathrm{Rh}-\mathrm{SrTiO}_{3}$ (c). (b) and (d) are enlargements of (a) and (c), respectively.

respectively [22]. Thus, in the rutile form of the $\mathrm{TiO}_{2}$ photocatalyst, $\mathrm{Cr}$ and $\mathrm{Ta}$ ions were incorporated at $\mathrm{Ti}$ sites. The XRD pattern of the synthesized $\mathrm{Rh}-\mathrm{SrTiO}_{3}$ powder indicated the photocatalyst formed a cubic crystal structure with a perovskite crystalline phase (Figure 1(c)). In Figure 1(d), the peak of $\mathrm{Rh}-\mathrm{SrTiO}_{3}$ shifted to a lower $2 \theta$ angle compared to non-doped $\mathrm{SrTiO}_{3}$. According to Konda et al. [23], two different species of $\mathrm{Rh}\left(\mathrm{Rh}^{3+}(0.0665 \mathrm{~nm}\right.$, the effective ionic radius) and a $\mathrm{Rh}$ species with a higher oxidation state than $\mathrm{Rh}^{3+}$, such as $\mathrm{Rh}^{4+}$ $(0.0615 \mathrm{~nm}$, the same)) replaced Ti sites as dopants. Thus, we considered that $\mathrm{Rh}$ ions were incorporated at $\mathrm{Ti}$ sites in $\mathrm{SrTiO}_{3}$.

XPS spectra were recorded to confirm the valency of constituent ions in $\mathrm{Cr}, \mathrm{Ta}-\mathrm{TiO}_{2}$ and $\mathrm{Rh}-\mathrm{SrTiO}_{3}$. Figures 2(a)-2(d) show the spectra for the Ti 2p, Cr 2p, Ta 4f, and O1s orbitals, respectively, of the prepared $\mathrm{TiO}_{2}, \mathrm{Cr}, \mathrm{Ta}-\mathrm{TiO}_{2}$, and commercially available $\mathrm{TiO}_{2}$ (99\% purity, Kanto Kagaku) after calibration with the $\mathrm{C} 1 \mathrm{~s}$ peak, derived from a conductive carbon-tape that had a binding energy of $284.5 \mathrm{eV}$. The spectra of $\mathrm{Ti} 2 \mathrm{p}$ of the prepared $\mathrm{TiO}_{2}$ and $\mathrm{Cr}, \mathrm{Ta}-\mathrm{TiO}_{2}$ were quite similar without any shoulder or peak at lower binding energy side (Figure 2(a)). Thus, the valency of $\mathrm{Ti}$ was $4+$ in the prepared $\mathrm{TiO}_{2}$ and $\mathrm{Cr}, \mathrm{Ta}-\mathrm{TiO}_{2}$ [24] [25]. In contrast, the commercial $\mathrm{TiO}_{2}$ had the peaks at lower binding energy side, indicating that it includes $\mathrm{Ti}^{3+}$ [24]. The $\mathrm{Cr} 2 \mathrm{p}$ peaks derived from $\mathrm{Cr}^{3+}(\mathrm{Cr}$ $2 \mathrm{p}_{3 / 2}$ at $576.9 \mathrm{eV}$ and $\mathrm{Cr} 2 \mathrm{p}_{1 / 2}$ at $\left.587.0 \mathrm{eV}[24]\right)$ and $\mathrm{Ta} 4 \mathrm{f}$ peaks from $\mathrm{Ta}^{5+}\left(\mathrm{Ta}_{4 \mathrm{f}} \mathrm{f}_{7 / 2}\right.$ at $26 \mathrm{eV}$ and $\mathrm{Ta} 4 \mathrm{f}_{5 / 2}$ at $28 \mathrm{eV}$ [26]) were observed only in $\mathrm{Cr}, \mathrm{Ta}^{-} \mathrm{TiO}_{2}$ as shown in Figure 2(b) and Figure 2(c), respectively. In Figure 2(d), the O 1s spectra are shown, however, they contain the spectra originated from the carbon tape. So, we are unable to discuss the valency of $\mathrm{O}$ and oxygen defects from these spectra. However, we consider that the prepared $\mathrm{TiO}_{2}$ and $\mathrm{Cr}, \mathrm{Ta}-\mathrm{TiO}_{2}$ do not have much oxygen defects because both of them contain $\mathrm{Ti}$ as $\mathrm{Ti}^{4+}$ and $\mathrm{Cr}, \mathrm{Ta}-\mathrm{TiO}_{2}$ has $\mathrm{Cr}$ and $\mathrm{Ta}$ as $\mathrm{Cr}^{3+}$ and $\mathrm{Ta}^{5+}$. 

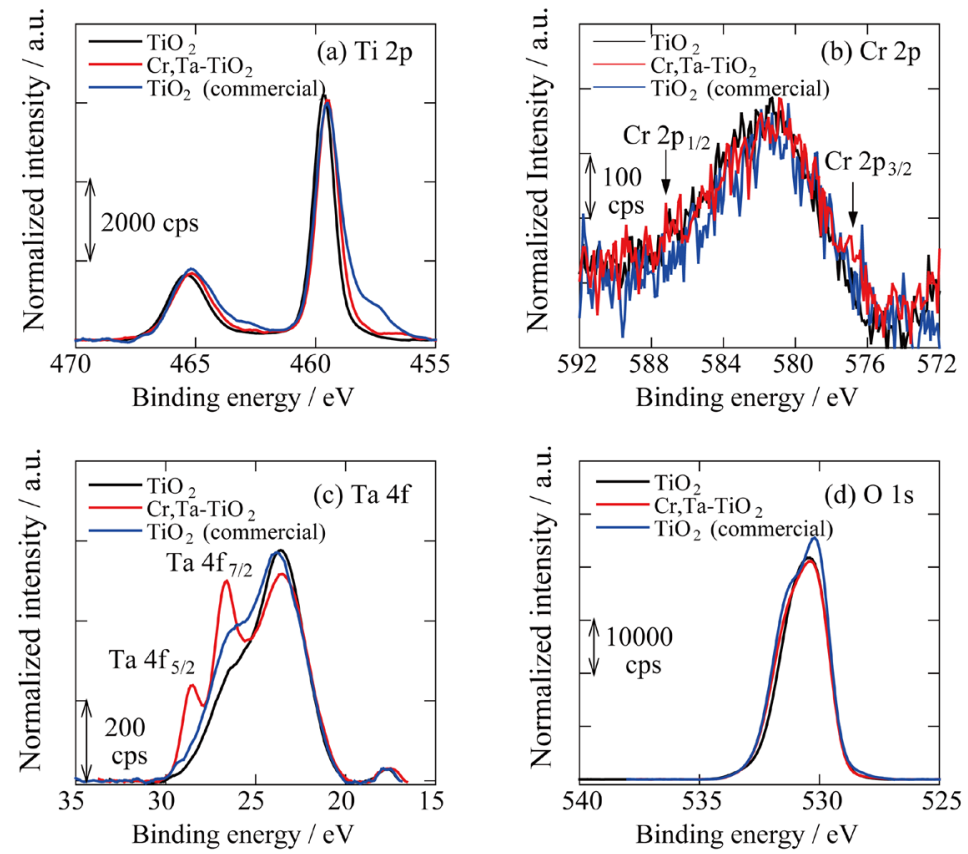

Figure 2. XPS spectra for (a) Ti 2p, (b) Cr 2p, (c) Ta 4f, and (d) O 1s of the prepared $\mathrm{TiO}_{2}, \mathrm{Cr}, \mathrm{Ta}-\mathrm{TiO}_{2}$, and commercial $\mathrm{TiO}_{2}$.

Figures 3(a)-3(d) show the spectra for the Sr 3d, Ti 2p, Rh 3d, and O1s orbitals, respectively, of the prepared $\mathrm{SrTiO}_{3}, \mathrm{Rh}-\mathrm{SrTiO}_{3}$, and commercially available $\mathrm{SrTiO}_{3}$ (99\% purity, Aldrich) after calibration with the C 1s peak similarly. The Sr 3d spectrum peak positions ( $\mathrm{Sr}_{3} \mathrm{~d}_{5 / 2}$ at $132 \mathrm{eV}$ and $\mathrm{Sr} 3 \mathrm{~d}_{3 / 2}$ at $134 \mathrm{eV}$ [27]) were quite similar among the prepared $\mathrm{SrTiO}_{3}, \mathrm{Rh}_{-} \mathrm{SrTiO}_{3}$, and the commercial $\mathrm{SrTiO}_{3}$. However, the spectrum shape of $\mathrm{Rh}-\mathrm{SrTiO}_{3}$ was different from those of both types of $\mathrm{SrTiO}_{3}$ (Figure 3(a)). According to Ehre et al., the $\mathrm{Sr} 3 \mathrm{~d}$ spectrum peak positions shift to higher energy region when $\mathrm{SrTiO}_{3}$ becomes amorphous [27]. So, the Sr-O bonding in $\mathrm{Rh}-\mathrm{SrTiO}_{3}$ would be looser than that in $\mathrm{SrTiO}_{3}$. As for $\mathrm{Ti} 2 \mathrm{p}, \mathrm{Rh}-\mathrm{SrTiO}_{3}$ had shoulders at higher energy side (Figure 3(b)), indicating the existence of the structure similar to $\mathrm{Ti}_{3} \mathrm{O}_{5}$ [28]. So, the oxygen defects were presumably incorporated in $\mathrm{Rh}-\mathrm{SrTiO}_{3}$. The $\mathrm{Rh} 3 \mathrm{~d}$ peaks were observed only in $\mathrm{Rh}_{-} \mathrm{SrTiO}_{3}$ as shown in Figure 3(c). In Figure 3(d), the observed $\mathrm{O}$ 1s spectra contain those originated from the carbon tape. So, we are unable to discuss the valency of $\mathrm{O}$ and oxygen defects from these spectra. However, as mentioned above, $\mathrm{Rh}-\mathrm{SrTiO}_{3}$ possibly contains oxygen defects.

The UV-visible absorption spectra of $\mathrm{TiO}_{2}, \mathrm{Cr}, \mathrm{Ta}-\mathrm{TiO}_{2}, \mathrm{Pt} / \mathrm{Cr}, \mathrm{Ta}-\mathrm{TiO}{ }_{2}$, $\mathrm{SrTiO}_{3}, \mathrm{Rh}-\mathrm{SrTiO}_{3}$, and $\mathrm{Ru} / \mathrm{Rh}-\mathrm{SrTiO}_{3}$ are shown in Figure 4. In the spectrum of $\mathrm{Cr}, \mathrm{Ta}-\mathrm{TiO}_{2}$, an absorption shoulder in the visible-light region and a negligible shift of the absorption edges were observed compared to that of $\mathrm{TiO}_{2}$. These findings indicate that the band-gap of $\mathrm{Cr}, \mathrm{Ta}-\mathrm{TiO}_{2}$ did not markedly differ from that of $\mathrm{TiO}_{2}$. In contrast, absorption in the entire range of visible light was observed for $\mathrm{Rh}-\mathrm{SrTiO}_{3}$, with a peak occurring at $\sim 600 \mathrm{~nm}$. Konda et al. reported the existence of two different doped $\mathrm{Rh}$ species as mentioned above is responsible for this spectral pattern [23]. The absorption with a peak occurring at $\sim 600 \mathrm{~nm}$ 

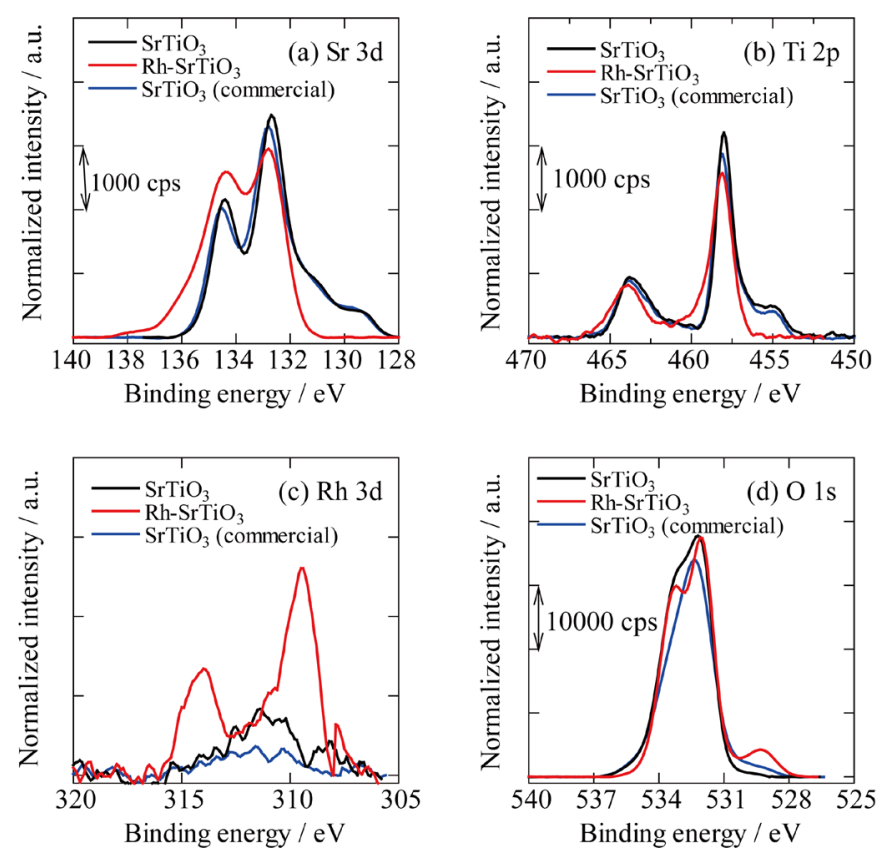

Figure 3. XPS spectra for (a) Sr 3d, (b) Ti 2p, (c) Rh 3d, and (d) O 1s of the prepared $\mathrm{SrTiO}_{3}, \mathrm{Rh}-\mathrm{SrTiO}_{3}$, and commercial $\mathrm{SrTiO}_{3}$.

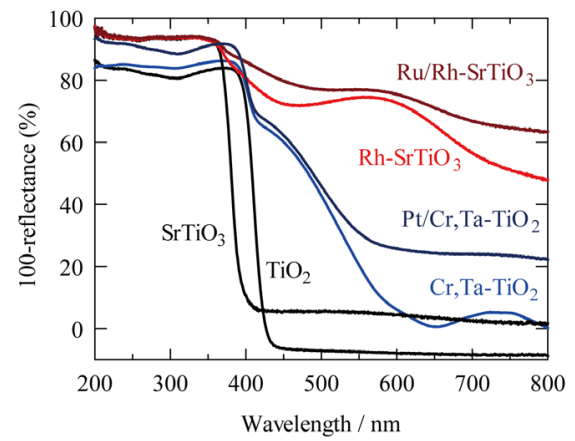

Figure 4. UV-visible absorption spectra of $\mathrm{TiO}_{2}, \mathrm{Cr}, \mathrm{Ta}-\mathrm{TiO}_{2}, \mathrm{Pt} / \mathrm{Cr}, \mathrm{Ta}-\mathrm{TiO}_{2}$, $\mathrm{SrTiO}_{3}, \mathrm{Rh}-\mathrm{SrTiO}_{3}$ and $\mathrm{Ru} / \mathrm{Rh}-\mathrm{SrTiO}_{3}$.

originated from the higher oxidation state of the Rh species, and the one with shorter wavelength region from $\mathrm{Rh}^{3+}$. Also, they asserted that the band-gap of $\operatorname{Sr}\left(\mathrm{Ti}_{0.99} \mathrm{Rh}_{0.01}\right) \mathrm{O}_{3}$ (i.e., $\mathrm{Rh}-\mathrm{SrTiO}_{3}$ in the present study) is narrowed by the partial overlap of $\mathrm{Rh} 4 \mathrm{~d}^{6}\left(\mathrm{Rh}^{3+}\right)$ and $\mathrm{O} 2 \mathrm{p}$ orbitals to form the $\mathrm{VB}$, resulting in a negative-potential shift of the VB top, which we confirmed in our previous study [19]. After depositing either Pt or $\mathrm{Ru}$ onto $\mathrm{Cr}, \mathrm{Ta}-\mathrm{TiO}_{2}$ or $\mathrm{Rh}-\mathrm{SrTiO}_{3}$, respectively, the absorption over a wider wavelength region $(>400 \mathrm{~nm})$ clearly increased, indicating the successful deposition of Pt or Ru.

STEM imaging of $\mathrm{Pt} / \mathrm{Cr}, \mathrm{Ta}-\mathrm{TiO}_{2}$ and $\mathrm{Ru} / \mathrm{Rh}-\mathrm{SrTiO}_{3}$ are shown in Figure 5(a) and Figure 5(b), respectively. The particle sizes of $\mathrm{Cr}, \mathrm{Ta}-\mathrm{TiO}_{2}$ and $\mathrm{Rh}-\mathrm{SrTiO}_{3}$ were estimated to have sizes of $\sim 100 \mathrm{~nm}$ and $\sim 50 \mathrm{~nm}$, respectively. The difference in particle sizes reflected the BET surface areas, which were observed to be 1.4 to $2.8 \mathrm{~m}^{2} / \mathrm{g}$ for $\mathrm{Cr}, \mathrm{Ta}-\mathrm{TiO}_{2}$ and $\mathrm{Rh}-\mathrm{SrTiO}_{3}$, respectively. Both $\mathrm{Cr}, \mathrm{Ta}-\mathrm{TiO}_{2}$ and $\mathrm{Rh}-\mathrm{SrTiO}_{3}$ particles were connected with each other, i.e., "necking growth" was 

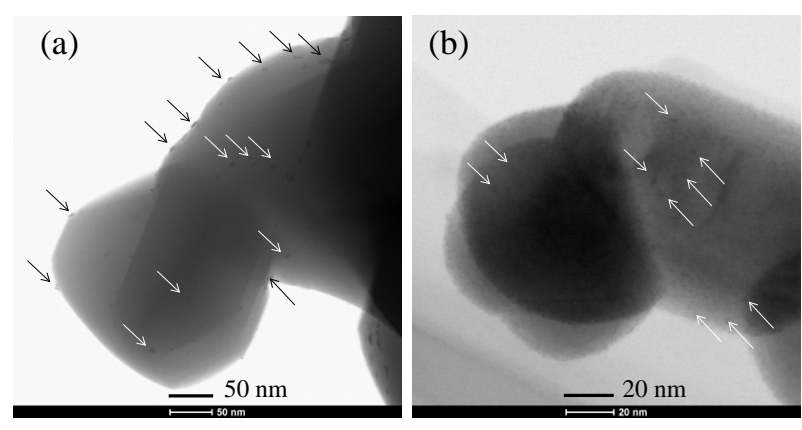

Figure 5. STEM images of $\mathrm{Pt} / \mathrm{Cr}, \mathrm{Ta}-\mathrm{TiO}_{2}$ (a) and $\mathrm{Ru} / \mathrm{Rh}-\mathrm{SrTiO}_{3}$ (b). Arrows show cocatalysts, either Pt or Ru.

observed due to rather high calcination temperature and long calcination time $\left(900^{\circ} \mathrm{C}\right.$ for $24 \mathrm{~h}$ and $1000^{\circ} \mathrm{C}$ for $10 \mathrm{~h}$ ). Nanometer order of $\mathrm{Pt}$ on $\mathrm{Cr}, \mathrm{Ta}-\mathrm{TiO}_{2}$ and $\mathrm{Ru}$ on $\mathrm{Rh}-\mathrm{SrTiO}_{3}$ could be observed (indicated by an arrow), and Pt sizes were larger than $\mathrm{Ru}$ the reason for which is not clear. From these observations, we also confirmed the deposition of $\mathrm{Pt}$ and $\mathrm{Ru}$ cocatalysts on $\mathrm{Cr}, \mathrm{Ta}-\mathrm{TiO}_{2}$ and $\mathrm{Rh}-\mathrm{SrTiO}_{3}$, respectively.

\subsection{Half Reactions of Water-Splitting}

We examined the evolution of $\mathrm{H}_{2}$ and $\mathrm{O}_{2}$ by $\mathrm{Ru} / \mathrm{Rh}-\mathrm{SrTiO}_{3}$ and $\mathrm{Pt} / \mathrm{Cr}, \mathrm{Ta}-\mathrm{TiO}_{2}$ in the presence of $\mathrm{I}^{-}$and $\mathrm{IO}_{3}^{-}$as sacrificial agents, respectively, under irradiation with visible light (420-nm LED) as shown in Figure 6. $\mathrm{H}_{2}$ evolution proceeded over $\mathrm{Ru} / \mathrm{Rh}-\mathrm{SrTiO}_{3}$ in the presence of $\mathrm{I}^{-}$. According to our previous paper [19], only the negligibly small amount of $\mathrm{H}_{2}$ was observed over bare $\mathrm{Rh}-\mathrm{SrTiO}_{3}$ in the presence of $\mathrm{I}^{-}$. Thus, we concluded that in the case of $\mathrm{Rh}-\mathrm{SrTiO}_{3}$, the cocatalyst $\mathrm{Ru}$ on $\mathrm{Rh}-\mathrm{SrTiO}_{3}$ was considered as the active site for $\mathrm{H}_{2}$ evolution. $\mathrm{O}_{2}$ evolution was detected for $\mathrm{Pt} / \mathrm{Cr}, \mathrm{Ta}-\mathrm{TiO}_{2}\left(\mathrm{Pt} / \mathrm{Ti}_{0.986} \mathrm{Cr}_{0.007} \mathrm{Ta}_{0.007} \mathrm{O}_{2}\right)$ in the presence of $\mathrm{IO}_{3}^{-}$. Figure 6 also includes the $\mathrm{O}_{2}$ evolution in the presence of $\mathrm{Pt} / \mathrm{Ti}_{0.982} \mathrm{Cr}_{0.009} \mathrm{Ta}_{0.009} \mathrm{O}_{2}$ quoted from our paper [20]. We could enhance the $\mathrm{O}_{2}$ evolution by changing the amounts of $\mathrm{Cr}$ and $\mathrm{Ta}$ at $\mathrm{Ti}$. The present $\mathrm{Cr}, \mathrm{Ta}-\mathrm{TiO}_{2}\left(\mathrm{Ti}_{0.986} \mathrm{Cr}_{0.007} \mathrm{Ta}_{0.007} \mathrm{O}_{2}\right)$ is the optimized composition for $\mathrm{H}_{2}$ evolution for now.

\subsection{Two-Step Overall Water Splitting}

We next examined water-splitting by the $\mathrm{Ru} / \mathrm{Rh}-\mathrm{SrTiO}_{3}$ and $\mathrm{Pt} / \mathrm{Cr}, \mathrm{Ta}-\mathrm{TiO}_{2}$ photocatalysts under visible-light irradiation (420-nm LED) for $\sim 350 \mathrm{~h}$ in the presence of $\mathrm{IO}_{3}^{-}\left(/ \mathrm{I}^{-}\right)$as a redox mediator (Figure 7). As shown in Figure 7 in the first cycle, $\mathrm{H}_{2}$ and $\mathrm{O}_{2}$ evolutions were initially supressed, but then increased. In contrast, in the second and third cycles, such an induction period for $\mathrm{H}_{2}$ and $\mathrm{O}_{2}$ evolutions was not observed. Although the reason for the delay in the evolutions was unclear, such phenomenon is frequently encountered. It may be due to the surface restructuring of the photocatalysts and/or cocatalysts, or due to the consumptions of holes and electrons for the residual contaminants on the surfaces of the photocatalysts and remaining oxygen in aqueous solution, respectively. In the third cycle, water-splitting activity decreased likely due to the 


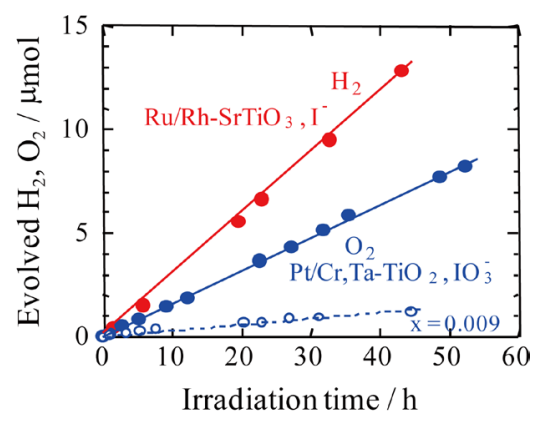

Figure 6. Time courses of $\mathrm{H}_{2}$ and $\mathrm{O}_{2}$ evolution resulting from the half reaction of waterbyRu/Rh-SrTiO 3 and $\mathrm{Pt} / \mathrm{Cr}, \mathrm{Ta}-\mathrm{TiO}_{2}$ photocatalysts irradiated with visible light (420-nm LED) in the presence of $\mathrm{I}^{-}$and $\mathrm{IO}_{3}^{-}$, respectively. $\mathrm{O}_{2}$ evolution was also included over $\mathrm{Pt} / \mathrm{Ti}_{0.982} \mathrm{Cr}_{0.009} \mathrm{Ta}_{0.009} \mathrm{O}_{2}$ irradiated with 420 nm LED light in the presence of $\mathrm{IO}_{3}^{-}$. The data were replotted from ref. [20].

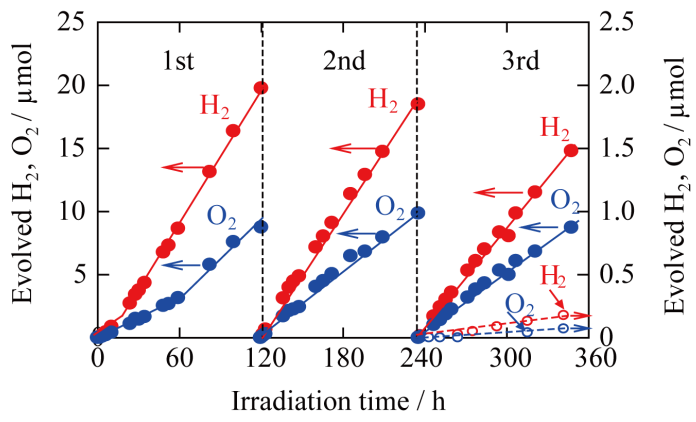

Figure 7. Time courses of $\mathrm{H}_{2}$ and $\mathrm{O}_{2}$ evolution resulting from photocatalytic overall water-splitting by $\mathrm{Ru} / \mathrm{Rh}-\mathrm{SrTiO}_{3}$ and $\mathrm{Pt} / \mathrm{Cr}, \mathrm{Ta}-\mathrm{TiO}_{2}$ photocatalysts under irradiation with visible light (420-nm LED). The reaction was allowed to proceed for $\sim 350 \mathrm{~h}$ with twice evacuations of the system. Those by $\mathrm{Pt} / \mathrm{Ti}_{0.96} \mathrm{Cr}_{0.02} \mathrm{Ta}_{0.02} \mathrm{O}_{2}$ and $\mathrm{Pt} / \mathrm{Ti}_{0.982} \mathrm{Cr}_{0.009} \mathrm{Ta}_{0.009} \mathrm{O}_{2}$ under 420 -nm LED light were also included in the 3 rd cycle. The data were replotted from ref. [20].

detachment of cocatalysts. In addition, the amount of water decreased and the partial sample powders attached to the inner wall of the reaction vessel as the repeating cycle increased. These are possible reasons for the decrement in the water-splitting activity in the third cycle. However, $\mathrm{H}_{2}$ to $\mathrm{O}_{2}$ were evolved in nearly stoichio-metric ( 2 to 1 ) amounts during each irradiation cycle.

It is well-known that the electron-and-hole transfers between the redox mediators needed for the two-step system and two types of photocatalysts are not efficient. In addition, the redox mediators usually give undesirable effects, e.g., backward reactions to form water from evolved $\mathrm{H}_{2}$ and $\mathrm{O}_{2}$. However, the $\mathrm{H}_{2}$ and $\mathrm{O}_{2}$ generation rates form the overall water-splitting reaction $(0.17$ and $0.09 \mu \mathrm{mol}$ $\mathrm{h}^{-1}$, respectively, in the second cycle) were more than one-half of those from the half reaction of water-splitting $\left(0.29\right.$ and $0.16 \mu \mathrm{mol} \cdot \mathrm{h}^{-1}$ for $\mathrm{H}_{2}$ and $\mathrm{O}_{2}$ rates, respectively, in Figure 6). To our knowledge, the efficiency of $\mathrm{H}_{2}$ and $\mathrm{O}_{2}$ generations from the overall water-splitting is rather high. The reason is still unclear; however an affinity between photocatalysts and the redox mediators in the constructed system would be suitable because it actually limits those combinations 
to several systems [13].

As determined by XRF analysis, the $\mathrm{Ru} / \mathrm{Rh}-\mathrm{SrTiO}_{3}$ sample contained $\mathrm{Ru}$ at a molar percentage of $1 \times 10^{-2}(1 \mathrm{~mol} \%)$. Therefore, because a total of $10 \mathrm{mg}$ of $\mathrm{Ru} / \mathrm{Rh}-\mathrm{SrTiO}_{3}$ was used in the water-splitting experiment as the $\mathrm{H}_{2}$-photocatalyst, the amount of $\mathrm{Ru}$ was $5 \times 10^{-1} \mu \mathrm{mol}$. As the total amount of $\mathrm{H}_{2}$ generated during the $350-\mathrm{h}$ experiment was $53 \mu \mathrm{mol}$, we estimated that the turnover number, the ratio of total amount of produced to $\mathrm{H}_{2}$ to that of $\mathrm{Ru}$ co-catalyst, was $\sim 100$, which exceeded 1 , indicating that this reaction proceeded catalytically. These results demonstrate that the photocatalytic overall watersplitting was achieved in this system. The possible mechanism for the overall water splitting by $\mathrm{Pt} / \mathrm{Cr}, \mathrm{Ta}-\mathrm{TiO}_{2}$ and $\mathrm{Ru} / \mathrm{Rh}-\mathrm{SrTiO}_{3}$ is schematically illustrated in Figure 8. Visible light-excited electrons in the conduction band of $\mathrm{Rh}-\mathrm{SrTiO}_{3}$ are thought to reduce $\mathrm{H}_{2} \mathrm{O}$ and generate $\mathrm{H}_{2}$ and holes in the valence band of $\mathrm{Cr}, \mathrm{Ta}-\mathrm{TiO}_{2}$ oxidize $\mathrm{H}_{2} \mathrm{O}$ and produce $\mathrm{O}_{2}$. In contrast, visible-light-excited holes in the $\mathrm{VB}$ of $\mathrm{Rh}-\mathrm{SrTiO}_{3}$ and electrons in the isolated $\mathrm{Cr} 3 \mathrm{~d}$ state contribute to the turnover of $\mathrm{I}^{-}$to $\mathrm{IO}_{3}^{-}$, respectively, and vice versa [19] [20].

When we compare our previous system $\left(\mathrm{Pt} / \mathrm{Ti}_{0.96} \mathrm{Cr}_{0.02} \mathrm{Ta}_{0.02} \mathrm{O}_{2}\right.$ and $\mathrm{Pt} / \mathrm{Ti}_{0.982} \mathrm{Cr}_{0.009} \mathrm{Ta}_{0.009} \mathrm{O}_{2}$ [20]) as indicated in the third cycle in Figure 7, the $\mathrm{H}_{2}$ and $\mathrm{O}_{2}$ generation rates acheved $\sim 100$ times higher in the present system, constructed by $\mathrm{Ru} / \mathrm{Rh}-\mathrm{SrTiO}_{3}$ and $\mathrm{Pt} / \mathrm{Cr}, \mathrm{Ta}-\mathrm{TiO}_{2}$. It is plausible that the composition of $\mathrm{Cr}, \mathrm{Ta}-\mathrm{TiO}_{2}\left(\mathrm{Ti}_{0.986} \mathrm{Cr}_{0.007} \mathrm{Ta}_{0.007} \mathrm{O}_{2}\right)$ was optimized as the $\mathrm{O}_{2}$ - photocatalyst and that the effective $\mathrm{Ru} / \mathrm{Rh}-\mathrm{SrTiO}_{3}$ was utilized as the $\mathrm{H}_{2-}$ photocatalyst. In addition, the commercial P-25 $\mathrm{TiO}_{2}$ (Degussa) and famous nitrogendoped $\mathrm{TiO}_{2}$ could evolve only a trace amount of $\mathrm{H}_{2}$ under the identical 420-nm LED (data not shown) and could not achieve the overall water-splitting. So the present system would be one of the candidates for obtaining $\mathrm{H}_{2}$ as it consists of environmental-friendly elements.

\section{Conclusions}

We established a two-step overall water-splitting system that is sensitive to visible light by utilizing $\mathrm{TiO}_{2}$-based and $\mathrm{SrTiO}_{3}$-based photocatalysts that simulta-

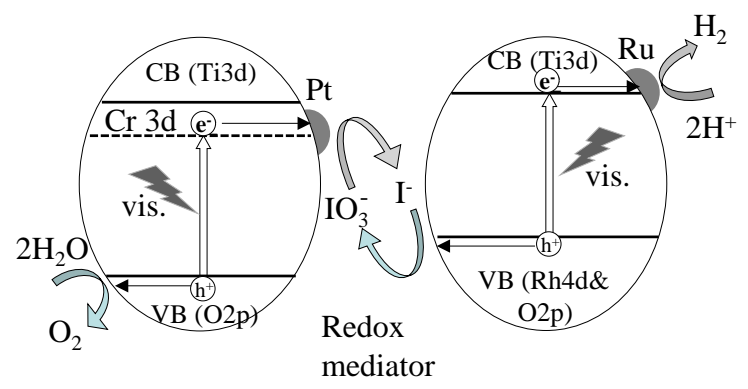

$\mathrm{Pt} / \mathrm{Cr}, \mathrm{Ta}-\mathrm{TiO}_{2} \quad \mathrm{Rh}-\mathrm{SrTiO}_{3}$

Figure 8. Schematic illustrations of spontaneous $\mathrm{H}_{2}$ and $\mathrm{O}_{2}$ evolution by $\mathrm{Pt} / \mathrm{Cr}, \mathrm{Ta}-\mathrm{TiO}_{2}$ and $\mathrm{Ru} / \mathrm{Rh}-\mathrm{SrTiO}_{3}$ under irradiation with visible light in the presence of $\mathrm{IO}_{3}^{-} / \mathrm{I}^{-}$redox mediator. 
neously evolve $\mathrm{H}_{2}$ and $\mathrm{O}_{2}$ at a molar ratio of $\sim 2$ to 1 efficiently in the presence of $\mathrm{IO}_{3}^{-}\left(/ \mathrm{I}^{-}\right)$. However, it is necessary to further enhance the visible light sensitivity. This will require the preparation of these $\mathrm{TiO}_{2}$ - and $\mathrm{SrTiO}_{3}$-based photocatalysts which are deficient-free, more highly crystallized, and smaller-sized particles. As is known, $\mathrm{TiO}_{2}$-based photocatalysts are attractive. So, we are now optimizing the types of dopants and concentrations to further enhance the visible-light sensitivity of $\mathrm{TiO}_{2}$-based photocatalysts. Moreover, we have recently developed a solid-state two-step overall water-splitting photocatalyst, in which the $\mathrm{H}_{2}$ - and $\mathrm{O}_{2}$-evolution photocatalysts were connected via silver. In this system, distilled water could be split without a redox mediator. The construction of solid-state systems using $\mathrm{TiO}_{2}$-based and $\mathrm{SrTiO}_{3}$-based photocatalysts in the present study may be advantageous for industrial and practical applications, as no chemicals are required as redox mediators.

\section{References}

[1] Fujishima, A. and Honda, K. (1972) Electrochemical Photolysis of Water at a Semiconductor Electrode. Nature, 238, 37-38. https://doi.org/10.1038/238037a0

[2] Kato, H., Asakusa, K. and Kudo, A. (2003) Highly Efficient Water Splitting into $\mathrm{H}_{2}$ and $\mathrm{O}_{2}$ over Lanthanum-Doped $\mathrm{NaTaO}_{3}$ Photocatalysts with High Crystallinity and Surface Nanostructure. Journal of the American Chemical Society, 125, 3082-3089. https://doi.org/10.1021/ja027751g

[3] Maeda, K., Teramura, K., Lu, D., Takata, T., Saito, N., Inoue, Y. and Domen, K. (2006) Photocatalyst Releasing Hydrogen from Water. Nature, 440, 295. https://doi.org/10.1038/440295a

[4] Yoneyama, H., Koizumi, M. and Tamura, H. (1979) Photolysis of Water on Illuminated Strontium Titanium Trioxide. Bulletin of the Chemical Society of Japan, 52, 3449-3450. https://doi.org/10.1246/bcsj.52.3449

[5] Kato, H. and Kudo, A. (2002) Visible-Light-Response and Photocatalytic Activities of $\mathrm{TiO}_{2}$ and $\mathrm{SrTiO}_{3}$ Photocatalysts Codoped with Antimony and Chromium. The Journal of Physical Chemistry B, 106, 5029-5034. https://doi.org/10.1021/jp0255482

[6] Niishiro, R., Konta, R., Kato, H., Chun, W.J., Asakura, K. and Kudo, A. (2007) Photocatalytic $\mathrm{O}_{2}$ Evolution of Rhodium and Antimony-Codoped Rutile-Type $\mathrm{TiO}_{2}$ under Visible Light Irradiation. Journal of Physical Chemistry C, 111, 17420-17426. https://doi.org/10.1021/jp074707k

[7] Li, L., Yan, J., Wang, T., Zhao, Z.J., Zhang, J., Gong, J. and Guan, N. (2015) Sub$10 \mathrm{~nm}$ Rutile Titanium Dioxide Nanoparticles for Efficient Visible-Light-Driven Photocatalytic Hydrogen Production. Nature Communications, 6, 5881/1-5881/10.

[8] Maeda, K., Takata, T., Hara, M., Saito, N., Inoue, Y., Kobayashi, H. and Domen, K. (2005) GaN:ZnO Solid Solution as a Photocatalyst for Visible-Light-Driven Overall Water Splitting. Journal of the American Chemical Society, 127, 8286-8287. https://doi.org/10.1021/ja0518777

[9] Sayama, K., Mukasa, K., Abe, R., Abe, Y. and Arakjawa, H. (2002) A New Photocatalytic Water Splitting System under Visible Light Irradiation Mimicking a Z-Scheme Mechanism in Photosynthesis. Journal of Photochemistry and Photobiology A: Chemistry, 148, 71-77. https://doi.org/10.1016/S1010-6030(02)00070-9

[10] Kato, H., Sasaki, Y., Iwase, A. and Kudo, A. (2007)Role of Iron Ion Mediator on Photocatalytic Overall Water Splitting under Visible Light Irradiation Using Z-Scheme Systems. Bulletin of the Chemical Society of Japan, 80, 2457-2464. 
https://doi.org/10.1246/bcsj.80.2457

[11] Kudo, A. (2007) Recent Progress in the Development of Visible Light Driven Powdered Photocatalysts for Water Splitting. International Journal of Hydrogen Energy, 32, 2673-2678. https://doi.org/10.1016/j.ijhydene.2006.09.010

[12] Maeda, K., Abe, R. and Domen, K. (2011) Role and Function of Ruthenium Species as Promoters with TaON-Based Photocatalysts for Oxygen Evolution in Two-Step Water Splitting under Visible Light. Journal of Physical Chemistry Letters, 115, 3057-3064. https://doi.org/10.1021/jp110025x

[13] Sasaki, Y., Nemoto, H., Saito, K. and Kudo, A. (2009) Solar Water Splitting Using Powdered Photocatalysts Driven by Z-Schematic Interparticle Electron Transfer without an Electron Mediator. Journal of Physical Chemistry C, 113, 17536-17542. https://doi.org/10.1021/jp907128k

[14] Iwase, A., Ng, Y.H., Ishiguro, Y., Kudo, A. and Amal, R. (2011) Reduced Graphene Oxide as a Solid-State Electron Mediator in Z-Scheme Photocatalytic Water Splitting under Visible Light. Journal of the American Chemical Society, 133, 1105411057. https://doi.org/10.1021/ja203296z

[15] Jia, Q., Iwase, A. and Kudo, A. (2014) $\mathrm{BiVO}_{4}-\mathrm{Ru} / \mathrm{SrTiO}_{3}$ : Rh Composite Z-Scheme Photocatalyst for Solar Water Splitting. Chemical Science, 5, 1513-1519. https://doi.org/10.1039/c3sc52810c

[16] Kobayashi, R., Tanigawa, S., Takashima, T., Ohtani, B. and Irie, H. (2014) Silver-Inserted Heterojunction Photocatalysts for Z-Scheme Overall Pure-Water Splitting under Visible-Light Irradiation. Journal of Physical Chemistry C, 118, 2245022456. https://doi.org/10.1021/jp5069973

[17] Kobayashi, R., Kurihara, K., Takashima, T., Ohtani, B. and Irie, H. (2016) A Silver-Inserted Zinc Rhodium Oxide and Bismuth Vanadium Oxide Heterojunction Photocatalyst for Overall Pure-Water Splitting under Red Light. Journal of Materials Chemistry $A, 4$, 3061-3067. https://doi.org/10.1039/C5TA08468G

[18] Kobayashi, R., Takashima, T., Tanigawa, S., Takeuchi, S., Ohtani, B. and Irie, H. (2016) A Heterojunction Photocatalyst Composed of Zinc Rhodium Oxide, Single Crystal-Derived Bismuth Vanadium Oxide, and Silver for Overall Pure-Water Splitting under Visible Light up to $740 \mathrm{~nm}$. Physical Chemistry Chemical Physics, 18, 27754-27760. https://doi.org/10.1039/C6CP02903E

[19] Hara, S., Yoshimizu, M., Tanigawa, S., Ni, L., Ohtani, B. and Irie, H. (2012) Hydrogen and Oxygen Evolution Photocatalysts Synthesized from Strontium Titanate by Controlled Doping and Their Performance in Two-Step Overall Water Splitting under Visible Light. Journal of Physical Chemistry C, 116, 17458-17463.

https://doi.org/10.1021/jp306315r

[20] Tanigawa, S. and Irie, H. (2016) Visible-Light-Sensitive Two-Step Overall Water-Splitting Based on Band Structure Control of Titanium Dioxide. Applied Catalysis B: Environmental, 180, 1-5. https://doi.org/10.1016/j.apcatb.2015.06.008

[21] Lei, N., Tanabe, M. and Irie, H. (2013) Visible-Light Induced Overall WaterSplitting Photocatalyst: Conduction Band-Controlled Silver Tantalate. Chemical Communications, 49, 10094-10096. https://doi.org/10.1039/c3cc45222k

[22] Shannon, R.D. and Prewitt, C.T. (1969) Effective Ionic Radii on Oxides and Fluorides. Acta Crystallographica Section B, 25, 925-946. https://doi.org/10.1107/S0567740869003220

[23] Konda, R., Ishii, T., Kato, H. and Kudo, A. (2004) Photocatalytic Activities of Noble Metal Ion Doped $\mathrm{SrTiO}_{3}$ under Visible Light Irradiation. Journal of Physical Chemistry B, 108, 8992-8995. https://doi.org/10.1021/jp049556p 
[24] Inturi, S.N.R., Boningari, T., Suidan, M. and Smirniotis, P.G. (2014) Flame Aerosol Synthesized $\mathrm{Cr}$ Incorporated $\mathrm{TiO}_{2}$ for Visible Light Photodegradation of Gas Phase Acetonitrile. Journal of Physical Chemistry C, 118, 231-242. https://doi.org/10.1021/jp404290g

[25] Gönüllü, Y., Haidry, A.A. and Saruhan, B. (2015) Nanotubular Cr-Doped $\mathrm{TiO}_{2}$ for Use as High-Temperature $\mathrm{NO}_{2}$ Gassensor. Sensors \& Actuators, B: Chemical, 217, 78-87. https://doi.org/10.1016/j.snb.2014.11.065

[26] Obata, K., Hiroshi, I. and Hashimoto, K. (2007) Enhanced Photocatalytic Activities of Ta, N Co-Doped $\mathrm{TiO}_{2}$ Thin Films under Visible Light. Sensors \& Actuators, B: Chemical, 339, 124-132. https://doi.org/10.1016/j.chemphys.2007.07.044

[27] Ehre, D., Cohen, H., Lyahovitskaya, V. and Lubomirsky, I. (2008) X-Ray Photoelectron Spectroscopy of Amorphous and Quasiamorphous Phases of $\mathrm{BaTiO}_{3}$ and $\mathrm{SrTiO}_{3}$. Physical Review B, 77, Article ID: 184106. https://doi.org/10.1103/PhysRevB.77.184106

[28] Moulder, J.F., Stickle, W.F., Sobol, P.E., Bomben, K.D., Chastain, L. and King Jr., R.C. (1995) Handbook of X-Ray Photoelectron Spectroscopy. Physical Electronics Inc., Chanhassen.

Submit or recommend next manuscript to SCIRP and we will provide best service for you:

Accepting pre-submission inquiries through Email, Facebook, LinkedIn, Twitter, etc. A wide selection of journals (inclusive of 9 subjects, more than 200 journals) Providing 24-hour high-quality service User-friendly online submission system Fair and swift peer-review system Efficient typesetting and proofreading procedure Display of the result of downloads and visits, as well as the number of cited articles Maximum dissemination of your research work

Submit your manuscript at: http://papersubmission.scirp.org/

Or contact msce@scirp.org 